
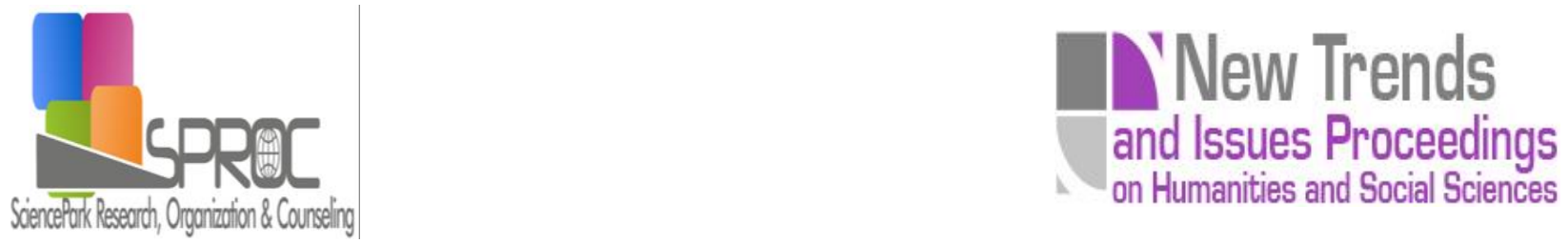

\title{
Educational tools for involving higher degree students within the Project Creative Conservation
}

Leonor Loureiro *

Ricardo Triães

Cláudia Falcão

Suggested Citation:

Abstract 
1. Introduction

2. The Classical Approach in Conservation and Restoration Teaching and Learning 
3. The Concept of Creative Conservation 


\section{Methodology}

\subsection{Workshop I}
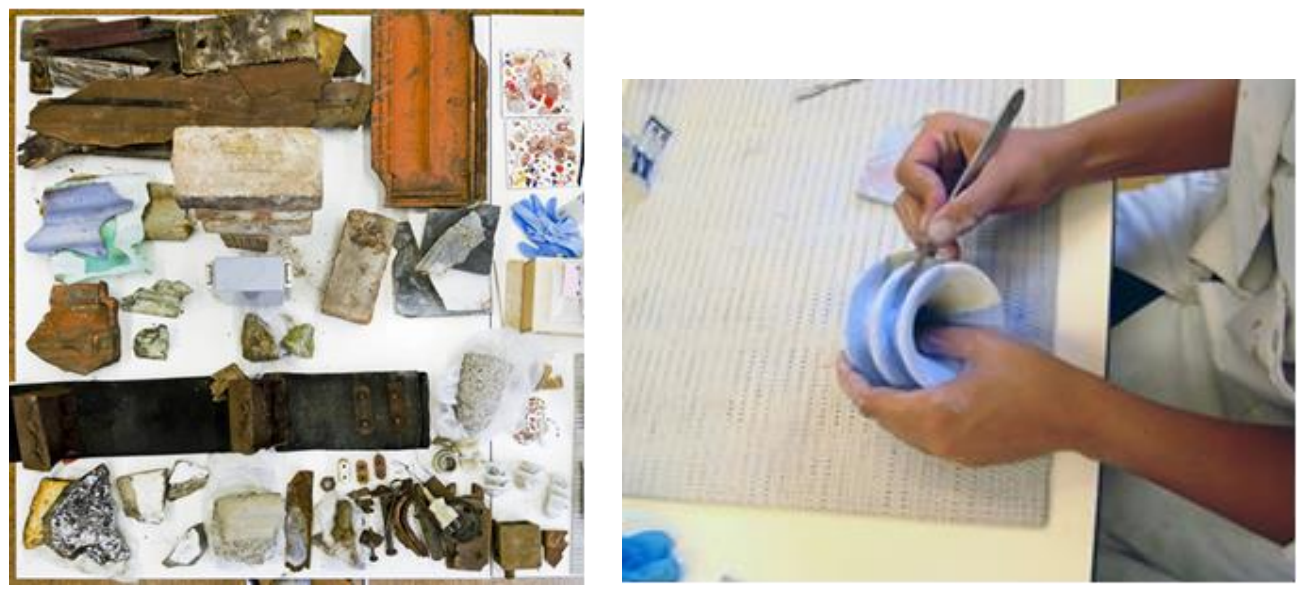

Figures 1 \& 2. Industrial remains before and during conservation work. 
5.2. Workshop II 
5.3. Workshop III

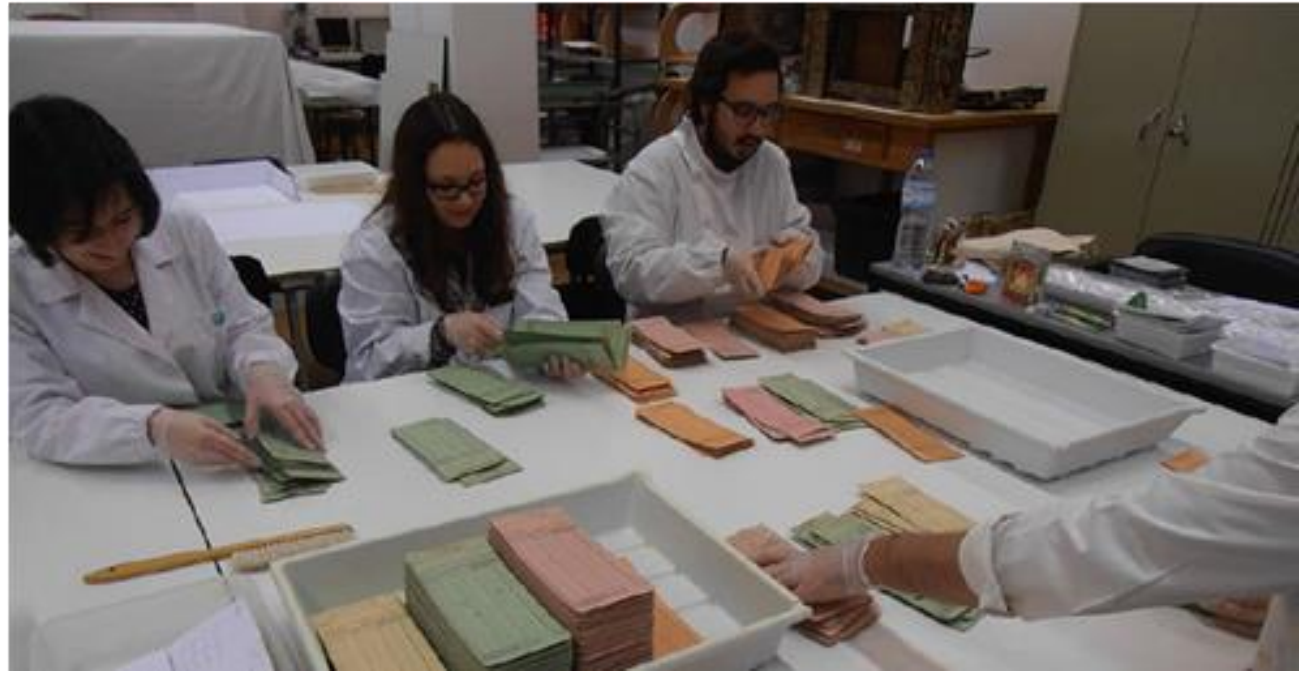

Figure 3. Some students during conservation work of the timecards.

I 

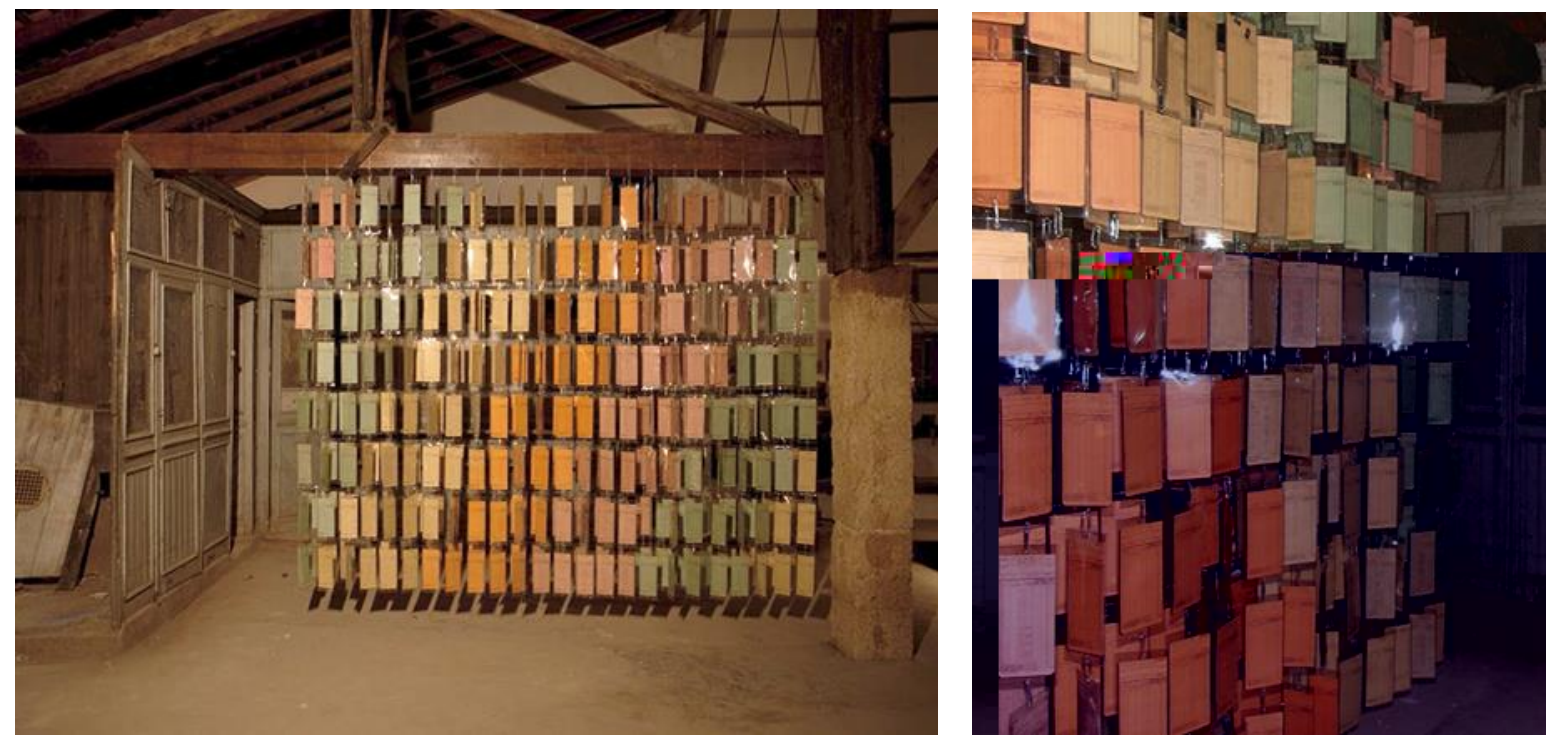

Figures 4 \& 5. The timecards "double curtain" installation at the exhibition.

\section{Results and Conclusions}


Acknowledgements 
1

References

$$
\overline{ }
$$

I

I

$$
\overline{ }
$$

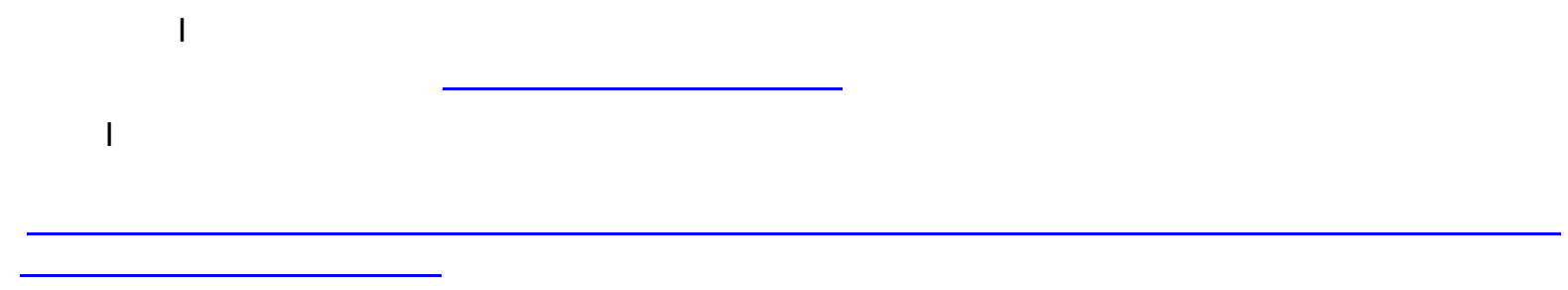

I

I 